\title{
Antimicrobial Resistance Profile of Extra-intestinal Escherichia coli Infections in a South Western Nigerian City
}

\author{
Motayo B. O. ${ }^{1}$, Ogiogwa I. J. ${ }^{1}$, Oke rentugba P. O. ${ }^{2}$, Innocent-Adie le H. C. ${ }^{2}$, Nwanze J. C. ${ }^{3}$, Onoh C. C. ${ }^{3}$, \\ Okonko I. O. ${ }^{2, *}$ \\ ${ }^{1}$ Department of Microbiology and Parasitology, Federal Medical Centre, Abeokuta, Ogun State, Nigeria \\ ${ }^{3}$ Department of Microbiology, University of Port Harcourt, East-West Road, P.M.B. 5323, Choba, Port Harcourt, Rivers State, Nigeria \\ ${ }^{4}$ Department of Pharmacology, Therap eutics, Igbinedion University, Okada, Edo State, Nigeria
}

\begin{abstract}
There is a general increase in the attention being paid to extraintestinal Escherichia coli infections; this is because recent reports have identified various reserviour sources of multi-resistant clones of $E$. coli carrying mobile genetic elements capable of epidemic spread. The public health implication of an outbreak of $E$. coli is better imagined than experienced. We have therefore analyzed all extraintestinal $E$. coli isolates and their resistance profile in Abeokuta, Ogun State, Southwestern Nigeria between March 2010 and November 2010. About 339 isolates of E. coli were isolated at the Microbiology Unit of Federal Medical center, Abeokuta using standard Bacteriological techniques and tested against various antibiotics including $3^{\text {rd }}$ generation Cephalosporins. Gender distribution was $105(31.0 \%)$ males and $234(39.0 \%)$ females, the highest recovery rate was recorded by age group 16-45 with 198(58.4\%), followed by above 45 years $76(22.4 \%)$ and lastly $0-15$ years $65(19.2 \%)$. Urine had the highest occurrence rate with $180(53.0 \%)$, followed by genital samples with $61(18.0 \%)$, and the least frequently isolated site was Blood, 27(8.0\%). Other samples tested were grouped together and recorded $35(10.4 \%)$. Gentamycin was the most active antibiotic with $41.3 \%$ susceptibility against all isolates tested, followed closely by A moxi/clav with $36.3 \%$ against all isolates tested. Very high resistance was recorded by the $\beta$-lactamases. There was poor sensitivity to the $3^{\text {rd }}$ generation cephalosporins, $32.0 \%$ of isolates were susceptible to Ceftazidime and $34.4 \%$ to Cefuroxime in age group $16-45$, and $46.4 \%$ susceptibility to ceftazidime were recorded against all isolates tested. In conclusion we report a high antimicrobial resistant rate in extraintestinal $E$. coli infection in Abeokuta with possible co-acquisition of different $\beta$-lactamase subtypes including ESBL and emerging Carbapenemases, the results of this study highlights the importance of regular surveillance of common pathogens such as $E$. coli in our environment.
\end{abstract}

Keywords Extraintestinal Escherichia Coli, Antimicrobial Resistance, $\beta$-lactamase, Abeokuta

\section{Introduction}

Enteriobacteriaceae is a broad group of heterogeneous medically important gram negative bacilli, consisting of 30 genera and more than 120 species[1]. This group of bacteria accommodates Escherichia coli is one of the most medically important bacteria known to man and animals alike, there have been associated with various diseases of man, but serve as a commensal in the intestinal tract of man and animals[2]. Pathogenic strains of E. coli causes both Intestinal and extraintestinal diseases such as Urinary tract infections (UTI), gastroenteritis, meningitis and sepsis, they

* Corresponding author:

mac2finney@y ahoo.com (Okonko I. O.)

Published online at http://journal.sapub.org/microbiology

Copyright (C) 2012 Scientific \& Academic Publishing. All Rights Reserved are able to do this by means of possession of several virulence factors such as Adhesins and exotoxins[1]. Pathogenic intestinal E. coli strains have been classified according to their disease manifestation and type of to xins produced, 5 main groups have been identified enterotoxigenic E. coli (ETEC), Enteropathogenic E. coli (EPEC), Enterohemorragic E. coli (EHEC), Enteroinvasive E. coli (EIEC), and Enteroaggregative E. coli (EAEC)[1]. The most commonly encountered strains are the EHEC and EPEC strains capable of causing life threatening diseases.

Several reports have demonstrated the severity of extraintestinal E. coli infections[3-4]. In the United States alone it is estimated that 6-8 million cases of uncomplicated UTI occur annually and about 130-175 million cases occur globally, with $E$. coli being responsible for over $80.0 \%$ of this figure[3]. Majority of E. coli sepsis have been traced to 
UTI and a few to gastroenteritis, the major reserviour of pathogenic strains of $E$. coli causing extraintestinal infection remains the alimentary tract, although evidence has shown that other sources such as contaminated food and food-animals like chicken can also cause extraintestinal $E$. coli infections[5-6]. It is an established fact that E. coli serves as a reserviour for the spread and dissemination of resistance phenotypes such as the dreaded ESBL and Carbapenemase resistance[7] this factors has also been recorded in extraintestinal E. coli infections, making treatment complicated and very expensive. Epidemics of extraintestinal E. coli infections have been recorded although this is not common[3]. The increasing global incidence of the shiga-toxin producing E. coli $0157: \mathrm{H} 7$ and its disease implications particularly in heamolytic ureamic syndrome (HUS) associated UTI infections has lead to an increase in the attention paid to extraintestinal E. coli infections, there is however a need to constantly review the antimicrobial resistance pattern of extraintestinal E. coli infections in developing countries such as Nigeria where surveillance of this condition is poor.

In Nigeria there are some reports of high level resistance in E. coli infections from extraintestinal sources[7], although more research data is still needed before any conclusions can be drawn on the exact multi-resistance profile of Nigerian E. coli isolates. In Abeokuta there are some interesting reports on ESBL producing isolates of $E$. coli from extraintestinal sites which has shown that multi-resistant extraintestinal E. coli infection are an established disease condition in Abeokuta[7, 8]. This prompted the objective of our study which is to review the antimicrobial resistance pattern of extraintestinal $E$. coli infection in a major tertiary hospital in Abeokuta, South West Nigeria.

\section{Materials and Methods}

\subsection{Study Design and Study Population}

We conducted a retrospective study of all E. coli infections from extraintestinal sites and their antibiotic susceptibility and resistance pattern at the Federal Medical center Abeokuta, from March 2010 to November 2010. Laboratory data were extracted from the records of the Medical Microbiology Unit of FMCA on patients of all ages and gender during the study period. All patient data were treated with the highest degree of confidentiality in accordance to the Belmont report[9].

\subsection{Bacteria Isolation and Identification}

All laboratory investigations were done retrospectively according to standard bacteriological techniques[10]. Briefly, freshly collected samples were inoculated onto Mac-Conkay, Blood and Chocolate agar; inoculated plates were incubated at $37^{\circ} \mathrm{C}$ aerobically while chocolate agar plates were incubated at $37{ }^{\circ} \mathrm{C}$ in a microaerophyllic condition for $48 \mathrm{hrs}$. Isolates were identified as $E$. coli following standard biochemical procedures [10].

\subsection{Antibiotic Susceptibility Testing}

Susceptibility testing was done on nutrient agar plates inoculated with 0.5 Mac Farland standard inoculum, testing was done following the Kirby-Bauer method for disk diffusion and results interpreted according to NCCLS guidelines[11]. Antibiotics tested include multidisc, Amoxicillin $(25 \mu \mathrm{g})$, Erythromycin $(25 \mu \mathrm{g})$, Tetracycline $(30 \mu \mathrm{g})$, Cotrimo xazole $(25 \mu \mathrm{g})$, Streptomycin $(10 \mu \mathrm{g})$, Gentamycin $(10 \mu \mathrm{g}) \quad$ A moxicillin/Clavunalate $(30 \mu \mathrm{g})$, Levoxac in $(30 \mu \mathrm{g})$, Ofloxac in $(30 \mu \mathrm{g})$, Nitrofurantion $(300 \mu \mathrm{g})$, supplied by (Abtek biological U.K.) and single disks Ceftazime $(30 \mu \mathrm{g})$, Cefuroxime $(30 \mu \mathrm{g})$, supplied by (Oxo id U.K.).

\section{Results Analysis}

During the period under review a total of 339 Escherichia coli isolates were recovered from extraintestinal sites, with a gender distribution of $105(31.0 \%)$ males and 234(39.0\%) females. Table 1 shows the age and gender distribution, the highest recovery rate was recorded by age group 16-45 with 198(58.4\%), followed by above 45 years $76(22.4 \%)$ and lastly $0-15$ years $65(19.2 \%)$.

Table 1. Distribution of extraintest inal Escherichia coli isolates according to Age and Gender

\begin{tabular}{|c|c|}
\hline Characteristics & No. (\%) \\
\hline \multicolumn{2}{|c|}{ Gender } \\
\hline Male & $105(39 \%)$ \\
\hline Female & $234(61 \%)$ \\
\hline \multicolumn{2}{|c|}{ Age group } \\
\hline $0-15$ & $65(19.2 \%)$ \\
\hline$>15-45$ & $198(58.4 \%)$ \\
\hline$>45$ & $76(22.4 \%)$ \\
\hline Total & $339(100.0)$ \\
\hline
\end{tabular}

Table 2 shows the distribution of isolates by sample site, from our results, Urine has the highest isolation rate for e. coli with $180(53.0 \%)$, followed by genital samples which includes high vaginal swab(HVS), Endocervical swab (ECS), and Semen, with a distribution of $61(18.0 \%)$, and the least frequently isolated site was Blood with $27(8.0 \%)$. Other samples tested which were grouped together; include sputum, Cerebrospinal flu id (CSF), Eye discharge and Ear swab, recorded 35(10.4\%).

Table 2. Distribution of extraintest inal E. coli isolates recovered from different sample sites

\begin{tabular}{|c|c|}
\hline Sample site & No. $(\mathbf{\%})$ \\
\hline Urine & $180(53.0)$ \\
\hline Blood & $27(8.0)$ \\
\hline Genital & $61(18.0)$ \\
\hline Wound & $36(10.6)$ \\
\hline Others & $35(10.4)$ \\
\hline Total & $\mathbf{3 3 9}(\mathbf{1 0 0 . 0})$ \\
\hline
\end{tabular}


Table 3. Antibiotic resistance pattern of Extraintest inal E. coli isolates against various Antibiotics

\begin{tabular}{|c|c|c|c|c|c|c|c|c|c|c|c|}
\hline \multirow{2}{*}{ Age } & \multicolumn{11}{|c|}{ Antibiotics $\{$ No teste $(\%$ resis $\tan t)\}$} \\
\hline & Amox & Ery & Tet & Sterp & Gen & $\mathbf{A m} / \mathbf{c v}$ & Lev & Oflox & Nit & $\mathbf{C a z}$ & Cef \\
\hline $0-15$ & $65(100.0)$ & $65(90.8)$ & $65(97.0)$ & $65(81.6)$ & $65(51.0)$ & $65(58.5)$ & $0(0.0)$ & $0(0.0)$ & $65(95.4)$ & $50(82.0)$ & $50(64.0)$ \\
\hline $16-45$ & 198(99.5) & $198(96.5)$ & $\begin{array}{c}198(97.0 \\
)\end{array}$ & $\begin{array}{c}198(89.0 \\
) \\
\end{array}$ & $\begin{array}{c}198(53.0 \\
)\end{array}$ & $\begin{array}{c}198(61.0 \\
)\end{array}$ & $198(61.6)$ & $\begin{array}{c}198(74.0 \\
)\end{array}$ & $\begin{array}{c}198(80.0 \\
)\end{array}$ & $\begin{array}{c}120(71.0 \\
)\end{array}$ & $\begin{array}{c}120(89.0 \\
)\end{array}$ \\
\hline$>45$ & $76(98.7)$ & $76(100.0)$ & $76(98.7)$ & $76(89.2)$ & $76(77.0)$ & $76(71.0)$ & $76(69.0)$ & $76(90.8)$ & $76(85.5)$ & $60(85.0)$ & $60(85.0)$ \\
\hline
\end{tabular}

Antibiotic sensitivity and resistance profiles of extraintestinal $E$. coli isolates according to age group revealed that Gentamycin was the most active antibiotic with $47.0 \%$ susceptibility in age group $16-45$ and $41.3 \%$ susceptibility against all isolates tested, followed closely by Amoxi/clav with $38.9 \%$ sensitivity in age group 16-45 and $36.3 \%$ against all isolates tested. Very high resistance was recorded by the $\beta$-lactamases, Erythromycin and tetracycline, with A moxicillin record ing 99.4\% resistance in all isolates tested and Erythromycin 96.2\% resistance against all isolates tested. The Quinolones also performed below average with Levoxacin record ing 38.4\% sensitivity in age group $16-45$ and $35.0 \%$ sensitivity against all isolates tested. There was poor even to the $3^{\text {rd }}$ generation cephalosporins, for instance $32.0 \%$ of isolates were susceptible to Ceftazidime and $34.4 \%$ susceptibility was recorded for Cefuroxime in age group 16-45, and only $46.4 \%$ susceptibility to ceftazidime was recorded against all isolates tested, details of the antibiotic susceptibility are shown inn table 3 below.

\section{Discussion}

The importance of $E$. coli as a pathogen of man over the years cannot be overemphasized, with its increasing ability to acquire and disseminate multiple resistant traits genetically to similar and often unrelated pathogenic bacteria[7, 12] has made its medical importance all so evident. In recent past attention was paid to $E$. coli as an enteric pathogen with its various forms of disease presentations. However with emerging evidence of severe infections often life threatening and more recently laboratory based evidence of outbreaks of extraintestinal $E$. coli infections, an example is the widely reported UTI outbreak caused by multiple serotypes of $E$. coli in California which lasted for about 4 months[5]. Epidemiologic reports have thus identified various reserviour sources of extraintestinal pathogenic E. coli infections, which include food animals such as chicken, pets, and feacal carriage by asymptomatic carriers [3].

In Abeokuta, there have several reports indicating the presence of multi-resistant strains of $E$. coli possessing EESBL and Amp $C$ properties isolated from extraintestinal sites [7, 13-14]. This prompted the objective of our study. From our report we reviewed $339 \mathrm{E}$. coli isolates causing extraintestinal infections from various anatomical sites in
Abeokuta. Gender distribution showed that females had more extraintestinal $E$. coli infections than males $(\mathrm{p}>0.05)$ with a frequency of $69.0 \%$ this is in agreement to a similar report from the same study site as our where enterohemorrhagic E. coli causing UTI was investigated[8]. This observation can be attributed to the female anatomy and the proximity of the female urethra and genital tract the anal region this allows for cross contamination in unhygienic situations and increased probability of UTI in direct comparis on to males. Age range distribution showed that the peadiatric age group had the lowest $E$. coli recovery rate with $19.2 \%$ while age range $16-45$ years had the highest, similar rates have been reported[8], this can also be attributed to the fact that more adult presented with various infectious diseases as compared to children during the study period, and the fact that adult wo men particularly pregnant women in their late trimester are more prone to UTI and bacteriuria[15-16].

Distribution according to sample site naturally recorded the highest rate in Urine samples with $53.0 \%$ followed by Genitals with $27.0 \%, 8.0 \%$ of recovered isolates came from Blood, this is consistent with previous reports that UTI are the principal extraintestinal disease of $\operatorname{man}[3,8]$. The rate of $8.0 \%$ recovered from blood also calls for attention as a previous report from our center placed $E$. coli as the second most incriminated bacteria in peadiatric sepsis in Abeokuta[14]. This report has further highlighted the importance of regular surveillance and strict infection control, because majority of $E$. coli sepsis have been reported to originate from untreated or poorly treated UTI, while significant number of paediatric $E$. coli sepsis originate from nosocomial infection during birth or shortly after child birth[14,17]. We also recovered a few isolates from sites such as CSF, which is indicate of the level of invasiveness achievable by $E$. coli if not quickly attended to.

Antibiotic susceptibility to the various antibiotics tested was generally poor with resistance rates as high as $99.4 \%$ against amoxicillin in all isolates tested, only the Aminoglcosides and the Quinolones performed fairly when compared to others, with Gentamycin recording $41.3 \%$ susceptibility to all tested and $47.0 \%$ in age group $16-45$. Amoxicillin clavunalic acid, which used to be very active against $\beta$-lactamase producers, was not very active against our isolates with a resistant rate of $61.0 \%$ in age group $16-45$ and $71.0 \%$ in age group 46 and above the fact that even the $3^{\text {rd }}$ generation cephalosporins were not very active 
amongst our isolates with Ceftazidime showing $71.2 \%$ resistance in age group $15-45$ and $76.7 \%$ resistance to all isolates tested confirms previous reports of ESBL and Carbapenemase producing E. coli dissemination in our study setting $[7,18]$.

Our current high level resistance to $\beta$-lacteamase antibiotics including expanded spectrum $\beta$-lactamases such as cephalosporins shows current high level ESBL circulation and possible co acquisition of possible Cabapenases resistance, this call for immediate response from local bacteriologist to draw out modalities for a robust study on the current molecular epidemiological profile of multip le drug resistant profiles, as this will give insight into possible novel multi-resistant genes such as New Deli $\beta$-lac, or $b l a_{\text {oxa }} 48$ acquired by our gram negative isolates an give insight into their origin and possible control and eradication.

\section{Conclusions}

We have reported a very high antimicrobial resistant rate in extraintestinal E. coli infection in Abeokuta, Ogun State, Southwestern Nigeria with possible co-acquisition of different $\beta$-lactamase subtypes including ESBL and emerging Carbapenemases, the results of this study highlights the importance of regular surveillance of common pathogens such as E. coli in our environment and call for an urgent investigation into the molecular epidemiology of gram negative multi-resistant bacteria such as $E$. coli. This will likely lead to the discovery of new rapidly transmissible resistant genes sun as NDM $\beta$-lactamase and can give insight into the origin of such resistant properties and their possible eradication measures.

\section{REFERENCES}

[1] Murray P.R., Rosenthal K.S., Kobayashi G.S., Pfaller M.A. (1998). Enteriobacteriacae: In Medical Microbiology $3^{\text {rd }}$ ed. Section IV. Pp232-244.

[2] Tadesse D. A., Zhso S., Tong E., Ayers S., Singh A., Bartholomew M. J., and P. F. McDermott. (2012) Antimicrobial drug resistance in Escherichia coli from Humans and food Animals, United States, 1950-2002.

[3] Vincent C., Boerlin., Daignault D., Dozois C.M., Dutil L., Galanakis C., Reid-Smith R.J., Tellier P., Ziebell K., and A.R. Manges. (2010) Food reserviour for Escherichia coli causing Urinary tract Infections. Emerging Infectious Diseases. 16(1); 88-95.

[4] Russo T.A., and Johnson J.R.(2003). Medical and economic impact of extraintestinal infections due to Escherichia coli: focus on an increasingly important economic problem. Microbes Infec. 5; 449-56.

[5] Manges A.R., Smith S.P., Lau B.J., Nuval. C.J. Eisenberg J.N., Dietrich P.S.(2007). Retail meat consumption and the acquisition of antimicrobial resistant Escherichia coli causing urinary tract infections: a case-control study. Food-borne Pathogens and Diseases, 4:419-31.

[6] Bergeron C.R., Prussing C., Boerlin P., Daignault D., Dutil L., Zhanel G.G. and A.R. Manges.(2012). Chicken as reserviuor for Extraintestinal Pathogenic Escherichia coli in Humans, Canada. Emerging Infectious Diseases. 18(3); 415-421.

[7] Akinduti P.A., Oluwadun A., Iwalokun B.A., Oluwaseun E., and K.O. Onagbesan (2011). Clonal dissemination of bla $\beta$-Lactamase strains among enteric isolates in Abeokuta, Nigeria. Res. J. Micro. 6(12); 919-925.

[8] Akinduti P.A., Akinbo J.A., Ejilude O.A., Mannie-Udoh M.I., Umahoin K.O., and J.O. Ogunbileje (2008). Prevalence of Enterohemorrhagic Escherichia coli O157: H7 Causing severe Urinarytract infection in Abeokuta, Nigeria. J. Am. Sci 4(2); 4-9.

[9] Document of the U.S department of Health, Education and Welfare, 1979.

[10] Cheesbrough M. (2000). Biochemical tests to identify bacteria. In District Laboratory practice in Tropical Countries Part 2. 7.5; 63070.

[11] National Committee for Clinical laboratory Standards. (2003). Performance standards for antimicrobial disk susceptibility testing. Suppliment M 100-S 12. Wayne. Pa:NCCLS

[12] Bradford P.A. (2001). Extended-spectrum $\beta$-lactamases in the $21^{\text {st }}$ century. Characterization epidemiology and epidemiology and detection of this important resistant threat. Clin. Microbiol. Rev. 14; 933-951.

[13] Akinduti P.A., Ejilude O., Motayo B.O., and A.F. Adeyakinu. (2012). Emerging Multiresistant Ampc Beta-Lactamase and Carbapenamase Enteric isolates in Abeokuta, Nigeria. Nature and Science. (2012). 10(7); 70-74.

[14] Motayo B.O., Akinduti P.A., Ogiogwa I.J., Akingbade O.A., Aboderin W.A. Adeyakinu F.A. and Akinbo. J.A. (2011). Bacteriological profile of blood cultures from Children with presumed septicaemia in a tertiary Hospital in Abeokuta, Nigeria. Nature and Science. 9(12); 141-144.

[15] Okonko I.O., Donbraye-Emmanuel., Ijandipe L.A., Ogun A.A., Adedeji A.O., Udeze A.O. (2009). Antibiotics Sensitivity and Resistance patterns of Uropathogens to Nitrofurantion and Naldixtic acid in Pregnant Women with Urinary tract infections in Ibadan, Nigeria. Middle-East Journal of Scientific Research. 4(2); 105-109.

[16] Adegboro Boaz. (2010). Enteriobacteriacea In: Microbiology. Ibadan University Press. Pp 240-246.

[17] Ireagbu K.C., Elegba Y.O., Babaniyi I.B.(2006). Bacteriological profile of neonatal septiceamia in a tertiary hospital in Nigeria. Afr. Health. Sci. 6(3); 151-154.

[18] Olowe O.A. and B.W. Aboderin, 2010. Detection of Extended Spectrum $\beta$-Lactamase Producing Strains of (Escherichia coli) and (Klebsiella sp.) in a Tertiary Health Centre in Ogun State. International Journal of Tropical Medicine, 5: 62-64. 